\title{
Liquid Crystal Thermography Measurement Uncertainty Analysis and Its Application to Turbulent Heat Transfer Measurements
}

\author{
Yu Rao ${ }^{1}$ and Yamin $\mathrm{Xu}^{2}$ \\ ${ }^{1}$ School of Mechanical and Power Engineering, Shanghai Jiaotong University, 800 Dongchuan Road, Shanghai 200240, China \\ ${ }^{2}$ School of Aeronautics and Astronautics, Shanghai Jiaotong University, 800 Dongchuan Road, Shanghai 200240, China
}

Correspondence should be addressed to Yamin Xu, xuym_2003@163.com

Received 13 July 2012; Accepted 27 August 2012

Academic Editor: Durga Ojha

Copyright ( $\odot 2012$ Y. Rao and Y. Xu. This is an open access article distributed under the Creative Commons Attribution License, which permits unrestricted use, distribution, and reproduction in any medium, provided the original work is properly cited.

\begin{abstract}
Liquid crystal thermography is an advanced nonintrusive measurement technique, which is capable of providing a high-accuracy continuous temperature field measurement, especially for a complex structured heat transfer surface. The first part of the paper presents a comprehensive introduction to the thermochromic liquid crystal material and the related liquid crystal thermography technique. Then, based on the aythors' experiences in using the liquid crystal thermography for the heat transfer measurement, the parameters affecting the measurement uncertainty of the liquid crystal thermography have been discussed in detail through an experimental study. The final part of the paper describes the applications of the steady and transient liquid crystal thermography technique in the study of the turbulent flow heat transfer related to the aeroengine turbine blade cooling.
\end{abstract}

\section{Introduction}

Thermochromic liquid crystal (TLC) is a cholesteric liquid crystal material. The cholesteric materials form a similar structure; however, under different temperatures the orientations of adjacent liquid crystal molecule planes are different with certain angles, which results in the reflection of different wavelengths of the visible spectrum of light when illuminated with white light and then show different colors [1-3]. Such optical characteristics of the TLC depend on its temperature and are repeatable and reversible. The accurate relations between the TLC colors and temperatures can be built through careful calibration experiments, which then can be used for precise temperature measurements of any surface.

Currently, the TLC can be provided with the operating temperature between $-30^{\circ} \mathrm{C}$ and $150^{\circ} \mathrm{C}$. The TLC may have the bandwidth (the active temperature range) of $1^{\circ} \mathrm{C}$ to $20^{\circ} \mathrm{C}$, in which the liquid crystal can be applied for the temperature measurements by changing color: smoothly from red to blue. The response time of TLC is about $3 \mathrm{~ms}$ [3]. Pure TLC materials are organic compounds that can easily degrade when exposed to chemical contamination and to ultraviolet (UV) light. Currently, people can use microencapsulation process to reduce the degradation. The microsized TLC particles are microencapsulated within transparent polymer shells (PMMA), which can significantly improve the stability of liquid crystal materials and make them capable of being handled easily. The TLC materials are currently supplied by the Hallcrest Ltd. (Glenview, USA) and Merck Ltd. (Pool, $\mathrm{UK})$.

TLC thermography, as a powerful nonintrusive optical technique for temperature measurement, is capable of providing a high-accuracy continuous temperature field measurement, especially for a complex structured heat transfer surface $[3,4]$. However, before the TLC is used for the temperature measurement, the hue-temperature calibration must be conducted. In the past two decades, many studies have been conducted on the calibration methods of the TLC. Rao and Zang [2], Camci et al. [5], Farina et al. [6], Behle et al. [7], Sabatino et al. [8], and Chan et al. [9] studied experimentally the effects of the lighting angles and viewing angles on the hue-temperature calibration curves of the TLCs. Roth and Anderson [10], Wiberg and Lior [11], Abdullah et al. [12], and Rao et al. [13] studied experimentally the effects of the coating thickness on the TLC hue-temperature calibration curves. These previous researches only indicated that the lighting angle and the coating thickness can significantly affect the TLC hue-temperature calibration curves. It should 


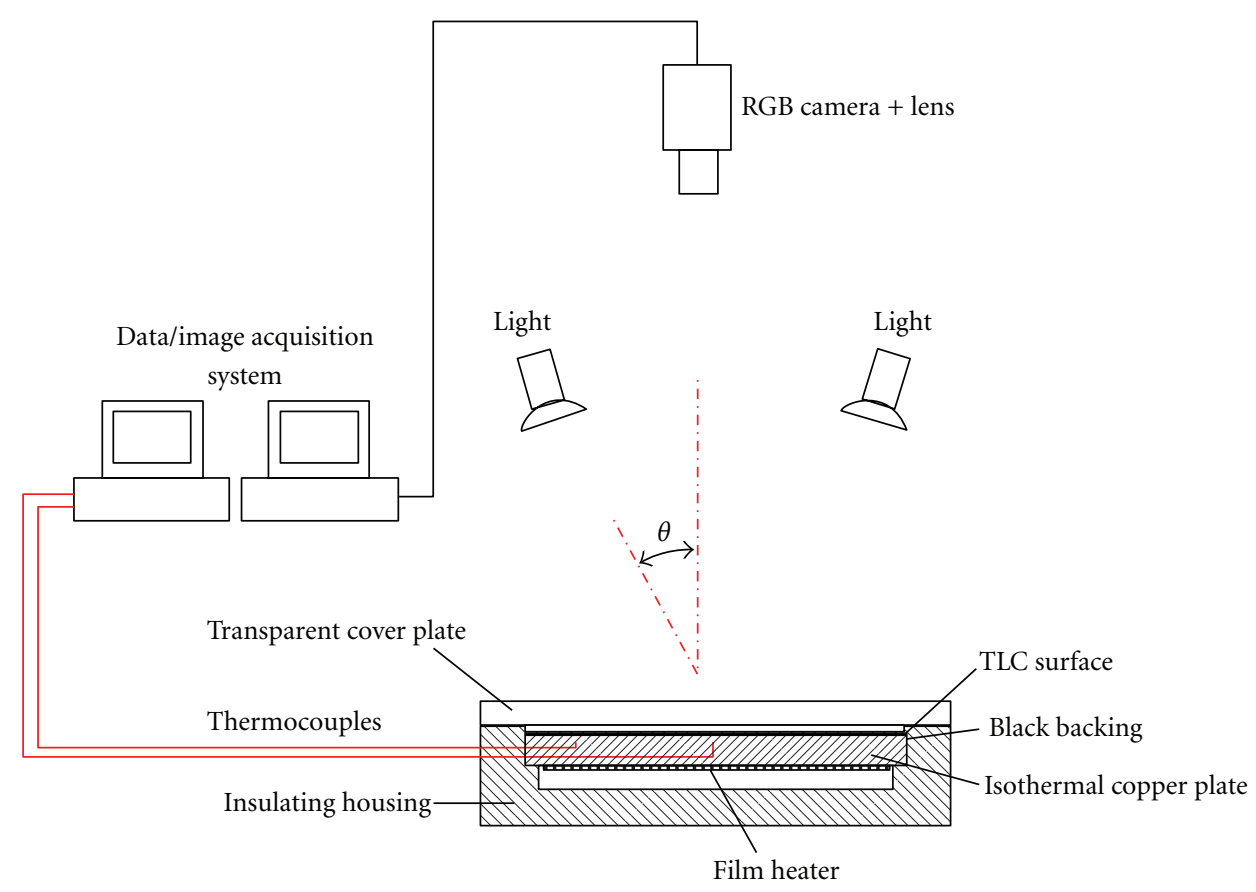

Figure 1: The TLC calibration experimental apparatus.

be pointed out that, though previous studies have indicated that such factors as lighting angles and coating thickness can influence the TLC hue-temperature calibration curves, reports on how the temperature measurement uncertainty of the TLC is influenced by those factors are still quite limited.

In the present paper, the first part is focused on the discussing on the effects of the measurement parameters on the measurement uncertainty of the TLC thermography, and the second part is focused on the application of the TLC thermography to the turbulent heat transfer studies.

\section{Parametric Analysis on the Measurement Uncertainty of TLC}

There are many factors that can affect the TLC thermography measurement uncertainty, such as the TLC bandwidth, the color imaging processing techniques, the coating thickness, the quality of the TLC coating, and the lighting angle, and so forth.

In order to study the effects of those parameters on the measurement uncertainty of the TLC, a calibration experimental apparatus was constructed as is shown in Figure 1. The TLC thermography system consists of a Hitachi (HVD30P) 3CCD RGB camera with a zoom lens, cold lighting source, a data acquisition system, an image acquisition system, and the related data processing software. The calibration device consists of a transparent Plexiglas cover plate, a copper plate with a film heater, and two type $\mathrm{K}$ thermocouples $(0.5 \mathrm{~mm}$ in diameter) with the measurement uncertainty of $\pm 0.1^{\circ} \mathrm{C}$.
By adjusting the voltage over the film heater, the copper plate's surface temperature can be controlled precisely and rapidly. The surface of the copper base plate was first painted black paint and then a layer of liquid crystal $(10-40 \mu \mathrm{m}$ in thickness). The supplied microencapsulated TLC slurry (Hallcrest SPN100R40C20W) has an operating temperature range of $40-60^{\circ} \mathrm{C}$. The changing color under the varying temperature is recorded by the 3CCD RGB camera. The TLC images are then processed by a self-developed data processing program, and the corresponding TLC hue-temperature relationship can be obtained. With the calibration experimental system, the authors have studied the effects of the influencing parameters on the measurement uncertainty of the TLC.

2.1. Effect of the Bandwidth of TLC on the Measurement Uncertainty. According to the working bandwidth, the TLC can be generally divided into the narrowband TLC and wideband TLC. A narrowband TLC has an active temperature range of $1^{\circ} \mathrm{C}$, and a wideband TLC can have an active temperature range of $5^{\circ} \mathrm{C}, 10^{\circ} \mathrm{C}$, or $20^{\circ} \mathrm{C}$. As the bandwidth of the TLC decreases, the sensitivity of hue to temperature increases, and then the measurement accuracy of the TLC increases. The previous literatures showed that the measurement uncertainty of the narrowband TLCs is about $\pm 0.1^{\circ} \mathrm{C}[12], \pm 0.1-$ $0.3^{\circ} \mathrm{C}$ [7], and $\pm 0.2-0.4^{\circ} \mathrm{C}$ [8] for the TLCs with the bandwidth of $5^{\circ} \mathrm{C}$ and $10^{\circ} \mathrm{C}$, respectively. The TLC with the bandwidth of $20^{\circ} \mathrm{C}$ has the measurement uncertainty of about $\pm 0.4-0.5^{\circ} \mathrm{C}[2]$.

2.2. Effect of Image Processing on the Measurement Uncertainty. Figure 2 shows the raw hue and the median filtered 


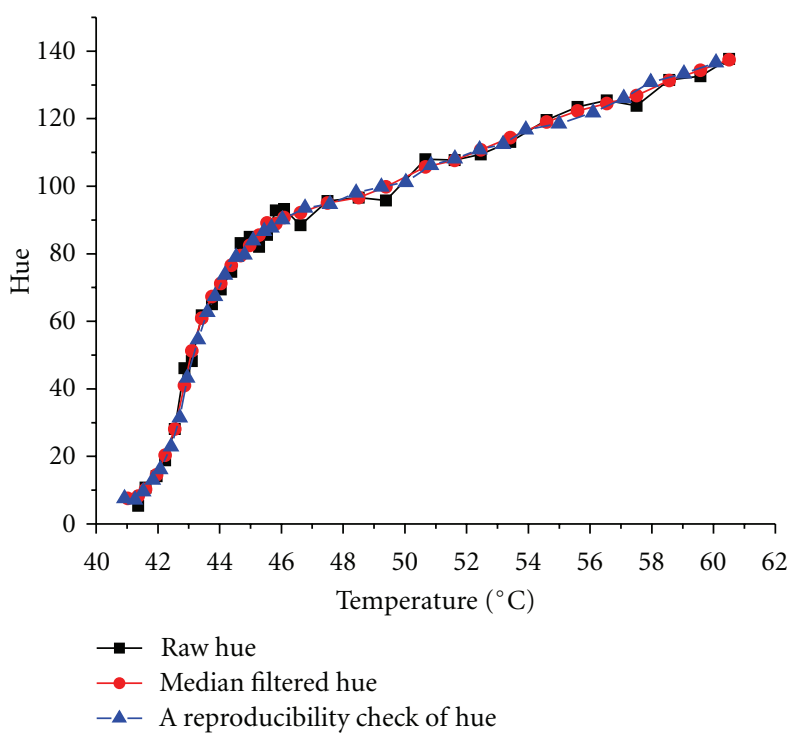

FIgURE 2: The raw hue and the median filtered hue calibrations of the TLC.

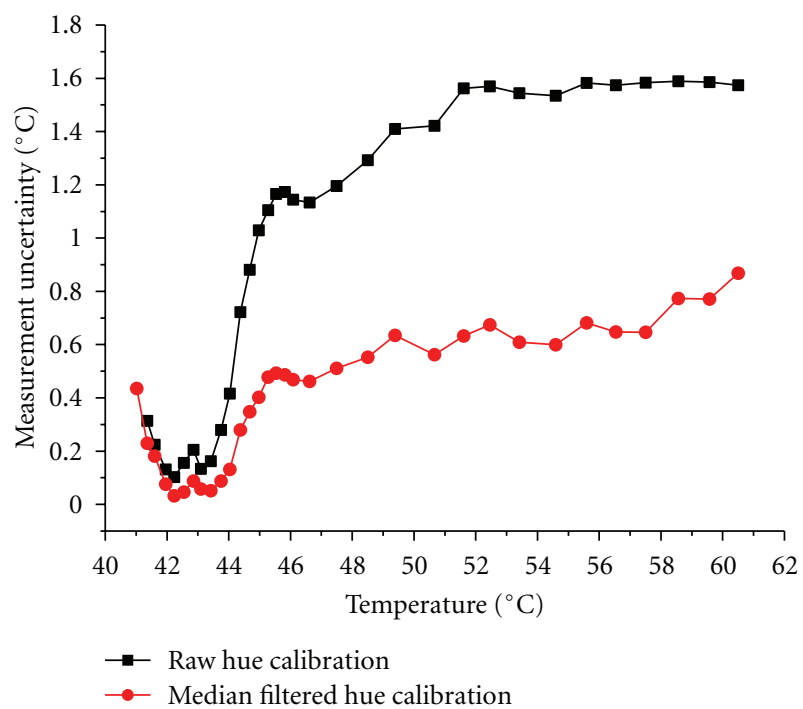

Figure 3: The measurement uncertainty in the raw hue and the median filtered hue calibrations.

hue calibrations of the TLC. The calibration experiment was done with the finely prepared TLC coating with a thickness of $25 \mu \mathrm{m}$, and the lighting angle is $27^{\circ}$. The hue value can be calculated by the following algorithms [14].

$$
\begin{aligned}
& \text { If } R=\text { Max, } \quad \text { Hue }=\frac{G-B}{6(R-\min (R, G, B))}, \\
& \text { If } G=\text { Max, } \quad \text { Hue }=\frac{2+B-R}{6(G-\min (R, G, B))}, \\
& \text { If } B=\text { Max, } \quad \text { Hue }=\frac{4+R-G}{6(B-\min (R, G, B))} .
\end{aligned}
$$

$R, G$, and $B$ are, respectively, red, green, and blue components of the liquid crystal image pixel.

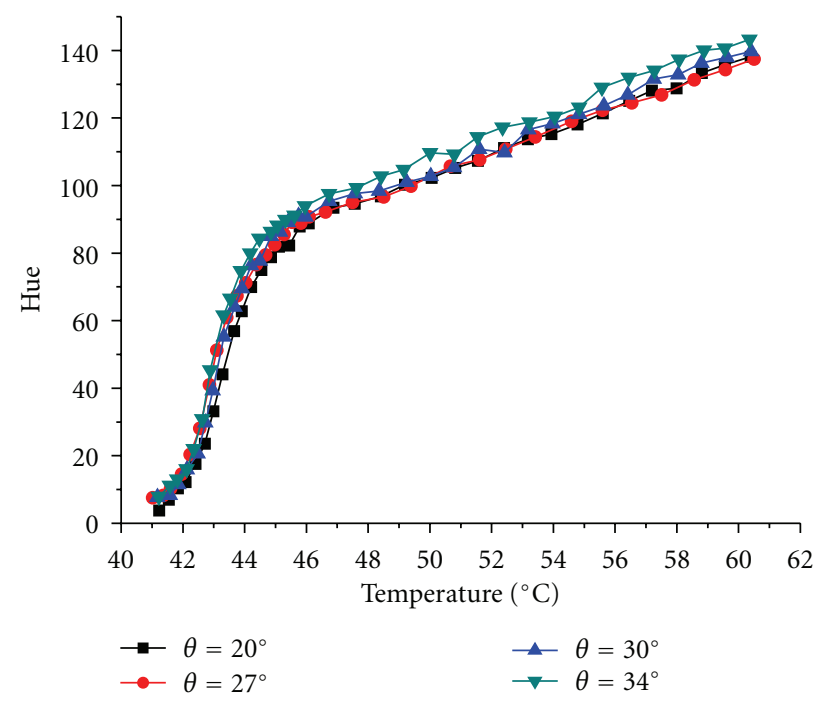

FIgURE 4: Effect of the lighting angle on the hue curve of the TLC coating.

It can be seen that the hue curve becomes much smoother than the unfiltered curve. The noise in the hue curves has been effectively removed. To check the reproducibility of the hue curve of the TLC, a second heating process was conducted. Figure 2 shows good reproducibility of the hue curve of the TLC.

To estimate the measurement uncertainty of the TLC, the method described in [8] was used. A series of constant temperature TLC color images $(100 \times 100$ pixels $)$ of calibration were examined. The constructed polynomial fitting of the temperature-hue relation was employed to convert each sample image to the corresponding temperature field, and the standard deviation in temperature was determined for each image. Using a 95\% confidence interval, the uncertainty for each discrete temperature/image was estimated as twice the standard deviation value.

Figure 3 shows the uncertainty in temperature measurement versus the actual temperature measurement. The measurement uncertainty based on the raw hue calibration ranges from 0.1 to $1.6^{\circ} \mathrm{C}$ with a mean of $0.98^{\circ} \mathrm{C}$, and the measurement uncertainty based on the median filtered hue ranges from 0.04 to $0.87^{\circ} \mathrm{C}$ with a mean of $0.42^{\circ} \mathrm{C}$. Therefore, a median filtering technique can significantly improve the measurement accuracy of the TLC. It is also noteworthy that the TLC shows a region-wise measurement uncertainty distribution. Over the temperature range of $41-45^{\circ} \mathrm{C}$, due to a higher sensitivity of hue to temperature, the TLC has a higher measurement accuracy, and the median filtered hue calibration has a mean measurement uncertainty of $0.17^{\circ} \mathrm{C}$.

2.3. Effect of Lighting Angle on the Measurement Uncertainty. The TLC calibration was conducted at various lighting angles of $20^{\circ}, 27^{\circ}, 30^{\circ}$, and $34^{\circ}$ with the finely prepared TLC coating based on the calibration experimental system as Figure 1 . Figure 4 shows the effect of the lighting angles on the hue calibration. The lighting angle has a notable effect on the 


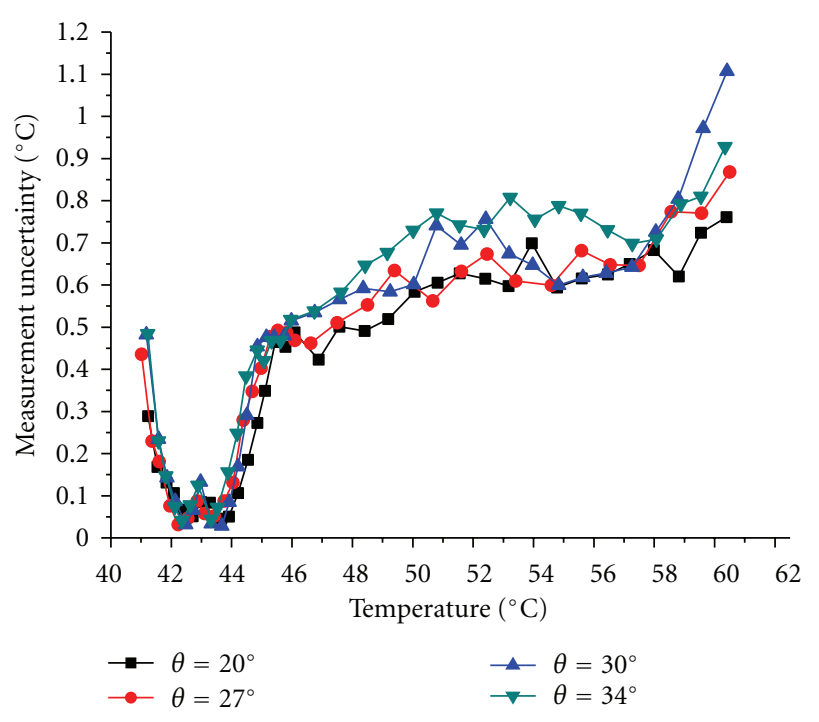

FIGURE 5: Effect of the lighting angle on the measurement uncertainty.

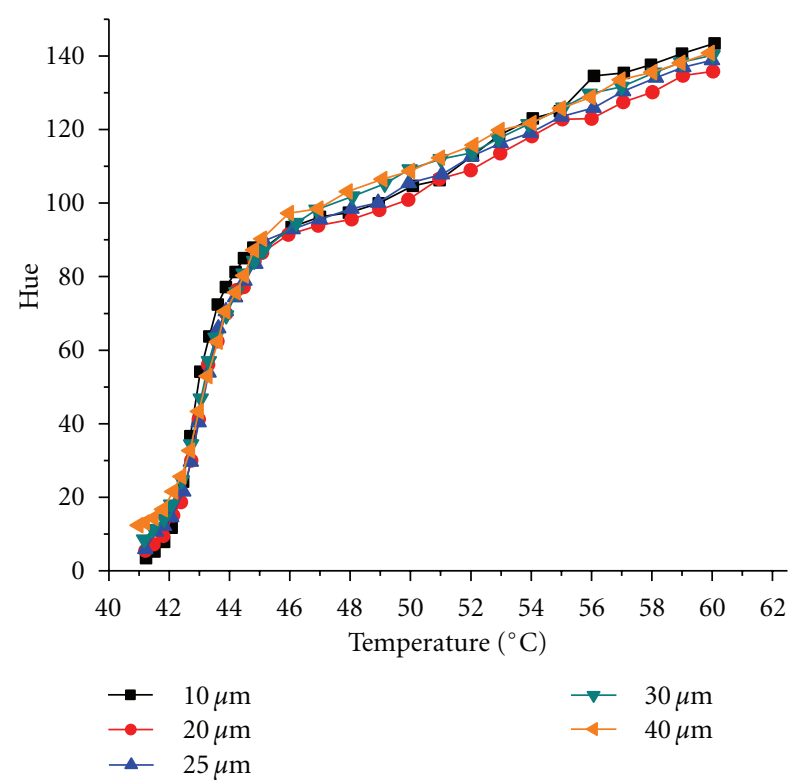

FIGURE 6: Effect of the TLC coating thickness on the hue curves.

hue-temperature curve, and as the lighting angle increases, the hue curve shifts upward.

Figure 5 shows the effect of the lighting angles on the uncertainty in temperature measurement versus the actual temperature measurement. It can be found that the measurement uncertainty increases with the lighting angle. The average measurement uncertainty with the lighting angle of $34^{\circ}$ is about $25 \%$ higher than that the lighting angle of $20^{\circ}$. The reason should be that as the lighting angle decreases, the lighting intensity on the coating of the TLC is stronger, which leads to a stronger reflection of the color signal and thereby a higher measurement accuracy. The effect of the lighting angle on the measurement uncertainty is more distinctive in

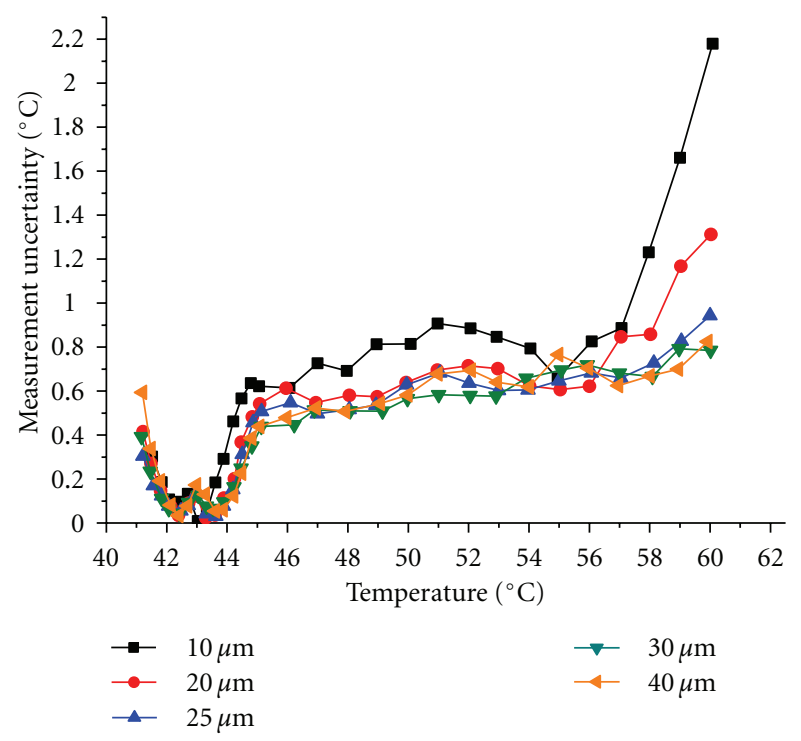

FIGURE 7: Effect of the TLC coating thickness on the measurement uncertainty.

the temperature range of $45-60^{\circ} \mathrm{C}$, which corresponds to the region of low TLC hue sensitivity. Therefore, in order to get a higher measurement accuracy, the lighting angle should be kept as small as possible providing the experimental space and arrangements allow.

Behle et al. [7] studied the effect of lighting angle within the range of $0-70^{\circ}$ on the temperature measurement uncertainty of the TLC. They have shown that the measurement uncertainty increases with the lighting angle, and the average measurement uncertainty with the lighting angle of $35^{\circ}$ is about $20 \%$ higher than that with the lighting angle of $20^{\circ}$, which agrees with the experimental results in the present paper.

2.4. Effect of TLC Coating Thickness on the Measurement Uncertainty. The coating thickness is also an important factor affecting the TLC measurement uncertainty. Figure 6 shows the hue curves of the TLC coatings with different thickness of $10 \mu \mathrm{m}, 20 \mu \mathrm{m}, 25 \mu \mathrm{m}, 30 \mu \mathrm{m}$, and $40 \mu \mathrm{m}$. The lighting angle is $27^{\circ}$. It can be found that the coating thickness has a notable effect on the hue-temperature curve, and as the coating thickness increases, the hue curve shifts upward.

Figure 7 shows the effect of coating thickness on the measurement uncertainty. It can be found that, except for the TLC coating thickness of $10 \mu \mathrm{m}$, the measurement uncertainties of the other TLC coatings show similar values with a mean of about $0.45^{\circ} \mathrm{C}$ over the calibratable temperature range of $41-60^{\circ} \mathrm{C}$, and a thicker TLC coating shows a relatively smaller measurement uncertainty. Figure 7 also indicates that the effect of the TLC coating thickness over $20 \mu \mathrm{m}$ is nondistinctive on the measurement uncertainty. The TLC coating with the thickness of $10 \mu \mathrm{m}$ shows a distinctively higher measurement uncertainty, which is because that the coating is very thin, leading to a weaker reflection of 
the color signal and correspondingly a higher noise level in the hue.

2.5. Effect of Coating Quality on the Measurement Uncertainty. Due to the congregation of the micro-sized TLC particles in the slurry, the suspended congregated particles can be of relatively larger size of 10-20 $\mu \mathrm{m}$. The TLC coating on the copper surface can be roughly prepared. The TLC coating can also be finely prepared by the following procedures: the TLC slurry was first diluted with an equal amount of distilled water and carefully mixed and fine-filtered; then the TLC slurry was repeatedly sprayed and dried on the black backing on the surface (1-5 $\mu \mathrm{m}$ TLC particle diameters). To examine the effect of the coating quality on the TLC hue curve calibration and the measurement uncertainty, comparative calibration experiments were conducted with a roughly prepared TLC coating and a finely prepared TLC coating under the same lighting condition (the lighting angle $=27^{\circ}$ ). Both coatings have the same thickness of $25 \mu \mathrm{m}$. Figure 8 shows the comparison of the hue curves of the rough coating and the fine coating. It is found that, the rough TLC coating and the fine TLC coating show different hue curves over the same monotonically calibratable temperature range. The fine TLC coating has a wider hue range, which means that the fine coating has a higher hue sensitivity to temperature and a higher resolution of the measurement.

Figure 9 shows the uncertainty in temperature measurement of the two coatings versus the actual temperature measurement. The measurement uncertainty of the fine coating ranges from $0.04^{\circ} \mathrm{C}$ to $0.87^{\circ} \mathrm{C}$ with a mean of $0.42^{\circ} \mathrm{C}$; however, that of the rough coating ranges from $0.1^{\circ} \mathrm{C}$ to $1.2^{\circ} \mathrm{C}$ with a mean of $0.72^{\circ} \mathrm{C}$. The fine coating shows a considerably higher measurement accuracy than the rough coating. The reason could be that compared with the fine coating, the surface of the rough coating is much rougher, and the thickness nonuniformity produces a larger noise level. Therefore, in order to get a high measurement accuracy, a finely prepared coating should be used for the actual TLC temperature measurement application.

\section{Application of TLC Thermography to the Turbulent Heat Transfer Measurement}

3.1. Steady and Transient TLC Thermography. The TLC thermography is capable of providing a high-accuracy and fullfield temperature measurement for structured heat transfer surfaces. Therefore, in the past 20 years the TLC thermography as a powerful tool for temperature measurement has been widely used for the turbulent heat transfer research for gas turbine/jet engine hot components' cooling design [1520].

Specifically, the application of the TLC thermography for the turbulent heat transfer study can be categorized as steady TLC thermography technique and transient TLC thermography technique.

3.1.1. Steady TLC Thermography Technique. When using the steady TLC thermography technique for the heat transfer

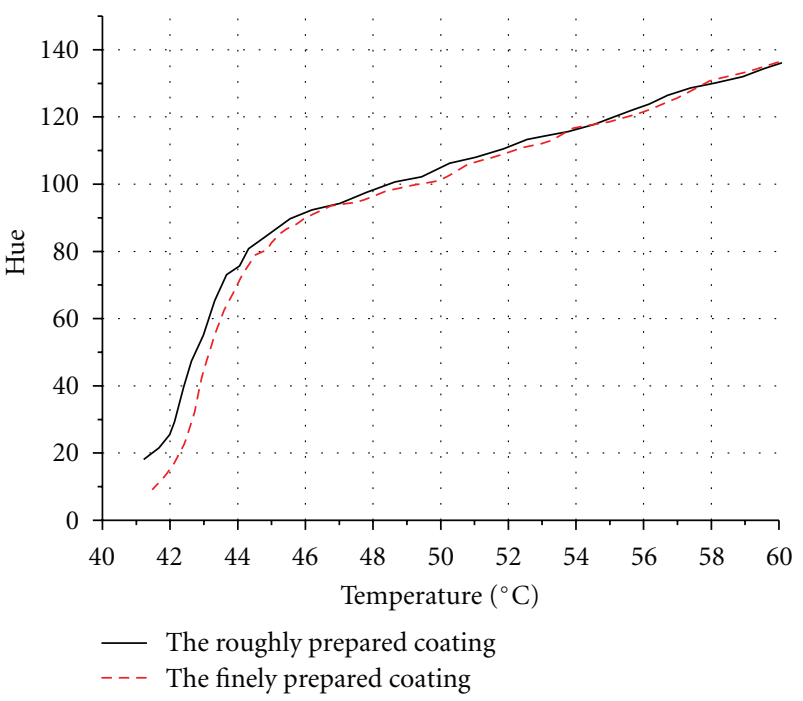

Figure 8: The hue curves comparison between the rough and fine TLC coatings.

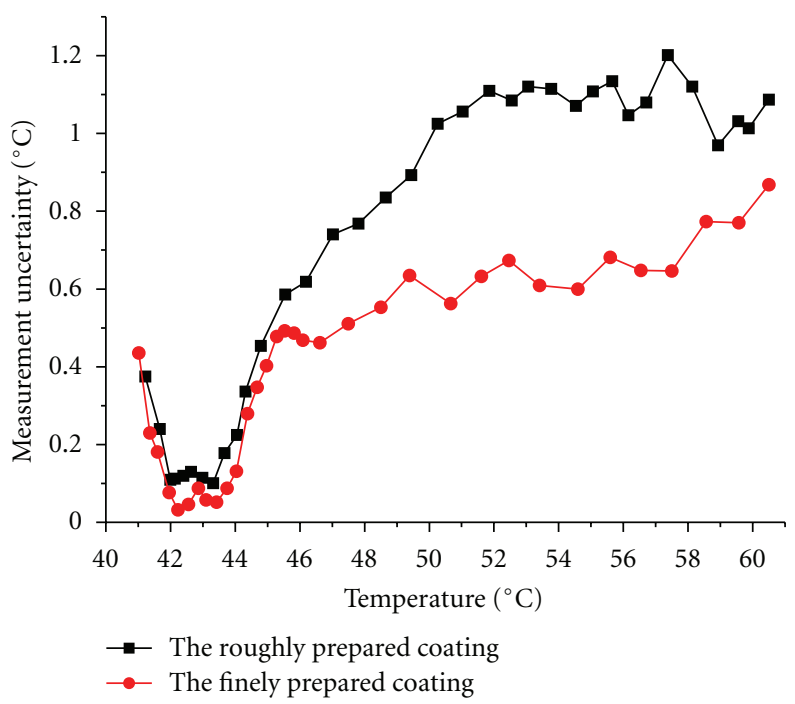

FIGURE 9: The measurement uncertainty for the rough and fine TLC coatings.

measurement, the TLC thermography usually works together with a film heater. The TLC provides the local wall temperature data, and the film heater provides a uniform surface heat flux condition, and then the heat transfer coefficient field can be obtained. However, in the situations with complex surface structures, a film heater could not be used, and then the local heat flux data should be obtained in another way. For example, in $[16,17]$ the heat flux data on the complex heat transfer surface with pin fins and dimples were obtained by a three-dimensional conjugate computation; by combining the temperature field obtained by the TLC thermography, the heat transfer coefficient field can then be determined.

3.1.2. Transient TLC Thermography Technique. The transient TLC thermography technique is an advanced and efficient 
heat transfer measurement technique, which is based on the one-dimensional solution of Fourier's heat conduction equation within a semi-infinite wall $[3,18-20]$ and can be used to the high-accuracy heat transfer measurements in complex cooling structures.

The local wall temperature can be measured by the TLC. The local heat transfer coefficients can be determined using the measured wall temperature and the solution of the onedimensional transient heat conduction equation for a semiinfinite solid. tion is

The one-dimensional transient heat conduction equa-

$$
k \frac{\partial^{2} T}{\partial x^{2}}=\rho c \frac{\partial T}{\partial t} .
$$

The boundary conditions are

$$
\begin{gathered}
t=0, \quad T=T_{0}, \\
x=0, \quad-k \frac{\partial T}{\partial x}=h\left(T_{B}-T_{w}\right), \\
x \rightarrow \infty, \quad T=T_{0},
\end{gathered}
$$

where $T$ is the temperature, $t$ is the time, and $k, \rho$ and $c$ are the solid wall thermal conductivity, density, and specific heat, respectively. Solving (2) with the boundary conditions, the dimensionless temperature at the convective boundary wall (at $x=0$ ) is obtained as folows:

$$
\frac{T_{w}-T_{0}}{T_{B}-T_{0}}=1-\exp \left(h^{2} \frac{t}{k \rho c}\right) \operatorname{erfc}\left(h \sqrt{\frac{t}{k \rho c}}\right) .
$$

Equation (4) is only valid for an ideal temperature step rise within the flow. However, in reality the thermocouples record a time-dependent variation of the mainstream temperature, which can be simulated by a series of small temperature step rise. By using Duhamel's superposition theorem, the solution for the heat transfer coefficient at every location is then represented as

$$
\begin{aligned}
T_{w}-T_{0}=\sum_{i=1}^{N}[ & 1-\exp \left(h^{2} \frac{\left(t-t_{i}\right)}{k \rho c}\right) \\
& \left.\times \operatorname{erfc}\left(h \sqrt{\frac{\left(t-t_{i}\right)}{k \rho c}}\right)\right]\left(T_{B, i}-T_{B, i-1}\right),
\end{aligned}
$$

where $T_{B, i}$ is the airflow bulk temperature at one specific time $t_{i}, T_{w}$ is the measured wall temperature by the time $t$ (indicated by the color change of the liquid crystals), and $T_{0}$ is the initial wall temperature. Solving (5) by an iteration method, the heat transfer coefficient $h$ can be determined. Since the TLC thermography can provide a full-field temperature data, therefore a full-field heat transfer coefficient data at the wall can be obtained.

\subsection{Examples of the TLC Thermography for Heat Transfer} Measurements. Pin fins and rib turbulators are the common heat transfer enhancement elements used in the gas turbine blade internal cooling channels, which produce strong

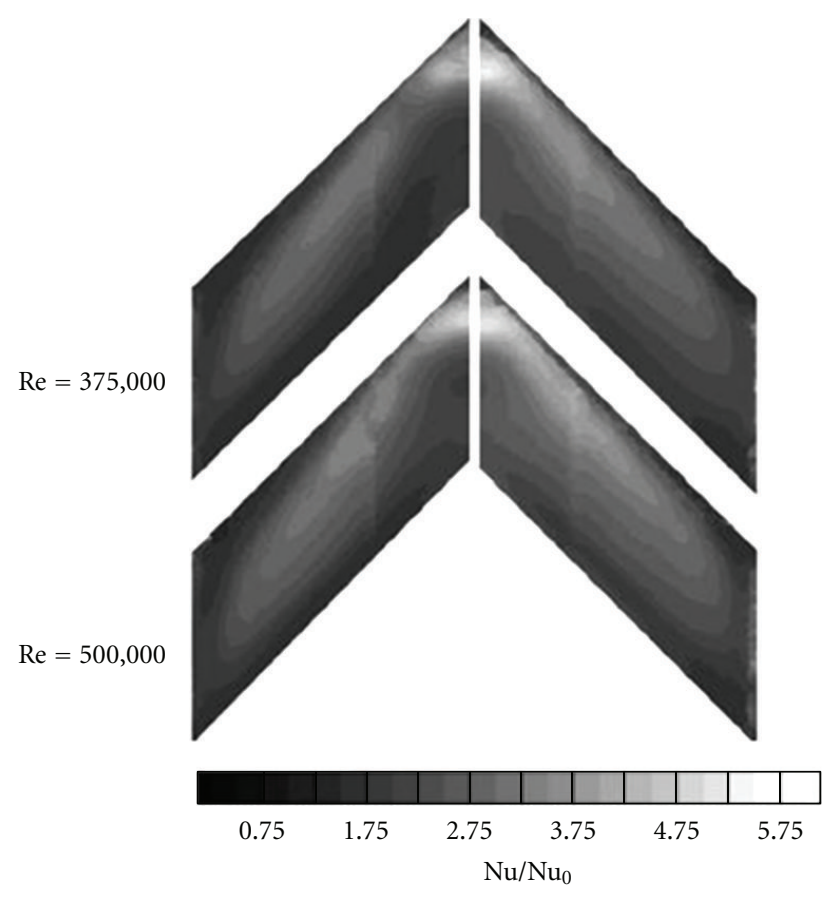

FIGURE 10: The local Nusselt number distribution on the surface with V-shaped rib turbulators [15].

turbulent flow in the cooling channels and significantly increase the convective heat transfer performance. Maurer et al. [15] studied the local heat transfer characteristics on the surface with $\mathrm{V}$-shaped rib turbulators by combining the steady TLC thermography technique with the stainless steel foil heater. In their study, the local wall temperature data was obtained by the TLC thermography; a uniform heat flux condition was provided by the thin stainless steel foil heater ( $25 \mu \mathrm{m}$ thickness). Based on the local wall temperature data and the local heat flux data, the local Nusselt number distribution on the surface with $\mathrm{V}$-shaped ribs was given by [15] as is shown in Figure 10. The measurement uncertainty for the heat transfer coefficient is about $12.5 \%$. In fact, in order to achieve a uniform distribution of the heat flux at the heating surface, the thickness of the film heater should be uniform and sufficiently small, so that the transverse heat conduction effects can be neglected.

In $[16,17]$, the authors showed the local heat transfer characteristics on the surface with pin fins and dimples, which were obtained by combining the steady TLC thermography technique with a three-dimensional CFD computation. Figure 11 shows the experimental schematic for the pin fin-dimple channel heat transfer measurement with the steady TLC thermography. The local temperature data on the heat transfer surface were obtained by the TLC thermography, and the local wall heat flux data were determined by the three-dimensional conjugate computation. An in situ calibration on the TLC thermography has been done before the heat transfer experiments, which indicates that the TLC has the highest temperature measurement accuracy within the temperature range of $41^{\circ} \mathrm{C}-45^{\circ} \mathrm{C}$. Therefore, in the convective heat transfer experiments the wall temperature 


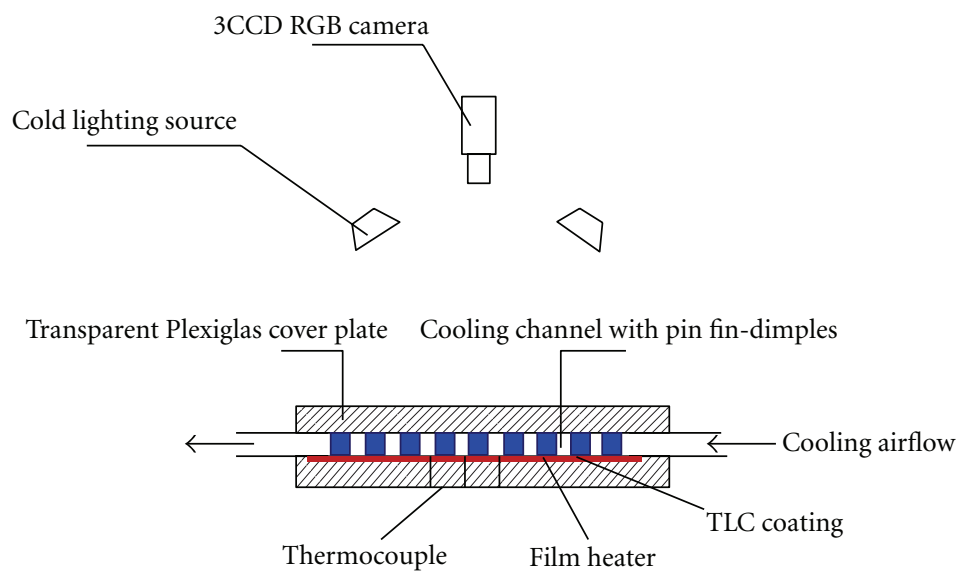

FIGURE 11: Experimental Schematic for the pin fin-dimple channel heat transfer measurement with the steady TLC thermography.

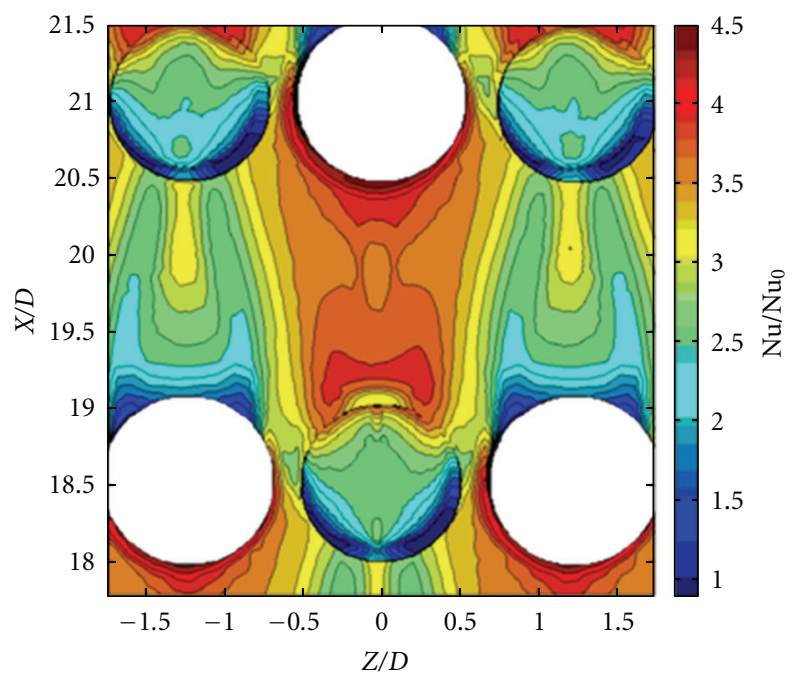

Figure 12: Local Nusselt number distribution on the heat transfer surface with pin fins and dimples $(\mathrm{Re}=18600)[16,17]$.

of the pin fin-dimple plate that was carefully controlled at about $43^{\circ} \mathrm{C}$. Based on the obtained local wall temperature and heat flux data, the local Nusselt number distribution on the surface with pin fin-dimple combined structures was obtained as is shown in Figure 12. The uncertainty on the heat transfer coefficient measurement is about $\pm 6.5 \%$, and the temperature measurement uncertainty is about $\pm 0.3^{\circ} \mathrm{C}$.

Schüler et al. [20] obtained the local heat transfer characteristics on the wall with angled ribs by using the transient TLC thermography technique. In their study, the air flow was heated up to $50-60^{\circ} \mathrm{C}$ through a mesh heater, and then flowed over a Plexiglas plate with angled ribs, which has an initial temperature of $18^{\circ} \mathrm{C}$. The narrowband TLC with the bandwidth of $1^{\circ} \mathrm{C}$ was sprayed on surface of the Plexiglas test plate, and the duration of the transient heat transfer measurement is 90-120s. Figure 13 shows the local Nusselt

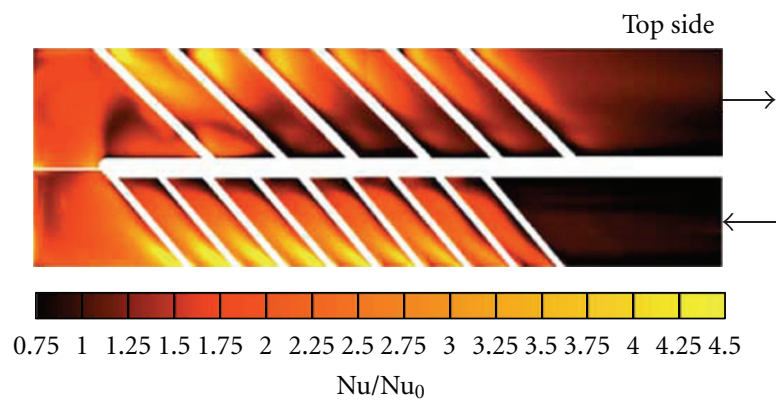

Figure 13: The local heat transfer characteristics on the wall with angled ribs measured by transient TLC thermography [20].

number field on the ribbed surface under turbulent flow condition. The measurement uncertainty of the Nusselt number is about $\pm 8.0 \%$, and the temperature measurement uncertainty is about $\pm 0.2^{\circ} \mathrm{C}$.

\section{Conclusions}

In the first part of the paper, a systematic introduction to the thermochromic liquid crystal (TLC) and the liquid crystal thermography has been presented. Based on the literature review and our experiences in the use of the TLC for the heat transfer measurements, the liquid crystal thermography calibration procedures have been detailedly described, and the parameters, which can influence the TLC temperature measurement uncertainty, have been investigated. The study shows that the use of an image noise reduction technique, the TLC coating thickness, the lighting angle, and the coating quality can distinctively influence the TLC hue calibration and the temperature measurement uncertainty. In the second part of the paper, examples of the applications of the steady and transient liquid crystal thermography techniques to the turbulent convective heat transfer measurements have been introduced. 


\section{Acknowledgment}

The research work was funded by the National Natural Science Foundation of China (Funding nos. 51176111 and 50806045).

\section{References}

[1] Hallcrest, Handbook of Thermochromic Liquid Crystal Technology, 1991.

[2] Y. Rao and S. Zang, "Calibrations and the measurement uncertainty of wide-band liquid crystal thermography," Measurement Science and Technology, vol. 21, no. 1, Article ID 015105, 2010.

[3] P. T. Ireland, A. J. Neely, D. R. H. Gillespie, and A. J. Robertson, "Turbulent heat transfer measurements using liquid crystals," International Journal of Heat and Fluid Flow, vol. 20, no. 4, pp. 355-367, 1999.

[4] P. T. Ireland and T. V. Jones, "Liquid crystal measurements of heat transfer and surface shear stress," Measurement Science and Technology, vol. 11, no. 7, pp. 969-986, 2000.

[5] C. Camci, K. Kim, and S. A. Hippensteele, "A new hue capturing technique for the quantitative interpretation of liquid crystal images used in convective heat transfer studies," Journal of Turbomachinery, vol. 114, no. 4, pp. 765-775, 1992.

[6] D. J. Farina, J. M. Hacker, R. J. Moffat, and J. K. Eaton, "Illuminant invariant calibration of thermochromic liquid crystals," Experimental Thermal and Fluid Science, vol. 9, no. 1, pp. 112, 1994.

[7] M. Behle, K. Schulz, W. Leiner, and M. Fiebig, "Color-based image processing to measure local temperature distributions by wide-band liquid crystal thermography," Applied Scientific Research, vol. 56, no. 2-3, pp. 113-143, 1996.

[8] D. R. Sabatino, T. J. Praisner, and C. R. Smith, "A high-accuracy calibration technique for thermochromic liquid crystal temperature measurements," Experiments in Fluids, vol. 28, no. 6, pp. 497-505, 2000.

[9] T. L. Chan, S. Ashforth-Frost, and K. Jambunathan, "Calibrating for viewing angle effect during heat transfer measurements on a curved surface," International Journal of Heat and Mass Transfer, vol. 44, no. 12, pp. 2209-2223, 2001.

[10] T. B. Roth and A. M. Anderson, "The effects of film thickness, light polarization, and light intensity on the light transmission characteristics of thermochromic liquid crystals," Journal of Heat Transfer, vol. 129, no. 3, pp. 372-378, 2007.

[11] R. Wiberg and N. Lior, "Errors in thermochromic liquid crystal thermometry," Review of Scientific Instruments, vol. 75, no. 9, pp. 2985-2994, 2004.

[12] N. Abdullah, A. R. A. Talib, H. R. M. Saiah, A. A. Jaafar, and M. A. M. Salleh, "Film thickness effects on calibrations of a narrowband thermochromic liquid crystal," Experimental Thermal and Fluid Science, vol. 33, no. 4, pp. 561-578, 2009.

[13] Y. Rao, S. Zang, and C. Wan, "Effect of coating thickness on the calibration and measurement uncertainty of a wide-band liquid crystal thermography," Chinese Optics Letters, vol. 8, no. 4, pp. 395-397, 2010.

[14] MATLAB 2007 R2007a help document, The MathWorks Inc.

[15] M. Maurer, J. von Wolfersdorf, and M. Gritsch, "An experimental and numerical study of heat transfer and pressure loss in a rectangular channel with V-shaped ribs," Journal of Turbomachinery, vol. 129, no. 4, pp. 800-808, 2007.

[16] Y. Rao, C. Wan, Y. Xu, and S. Zang, "Local heat transfer characteristics in channels with pin fin and pin fin-dimple arrays," in Proceedings of the ASME of Turbine Technical Conference and Exposition (GT'11), 2011.

[17] Y. Rao, C. Wan, Y. Xu, and S. Zang, "Spatially-resolved heat transfer characteristics in channels with pin fin and pin findimple arrays," International Journal of Thermal Sciences, vol. 50, no. 11, pp. 2277-2289, 2011.

[18] S. C. Jenkins, I. V. Shevchuk, J. von Wolfersdorf, and B. Weigand, "Transient thermal field measurements in a high aspect ratio channel related to transient thermochromic liquid crystal experiments," Journal of Turbomachinery, vol. 134, Article ID 031002, 10 pages, 2012.

[19] S. V. Ekkad and J. C. Han, "A transient liquid crystal thermography technique for gas turbine heat transfer measurements," Measurement Science and Technology, vol. 11, no. 7, pp. 957$968,2000$.

[20] M. Schüler, S. O. Neumann, and B. Weigand, "Experimental investigations of pressure loss and heat transfer in a $180^{\circ}$ bend of a ribbed two-pass internal cooling channel with enginesimilar cross-sections," Journal of Power and Energy A, vol. 223, no. 6, pp. 709-719, 2009. 

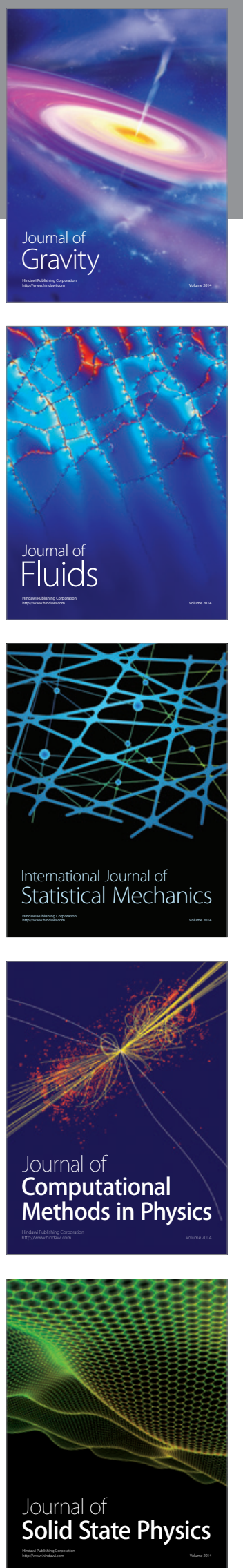

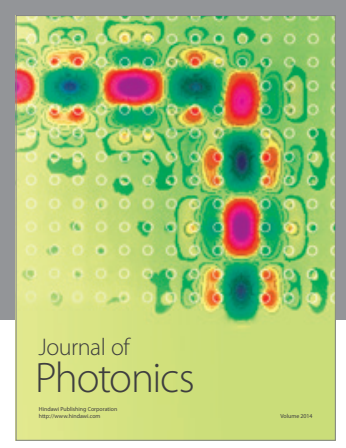

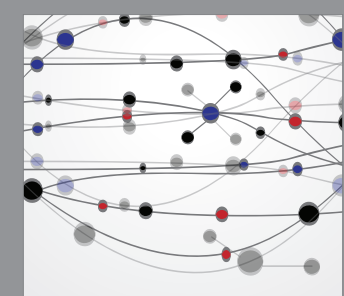

The Scientific World Journal
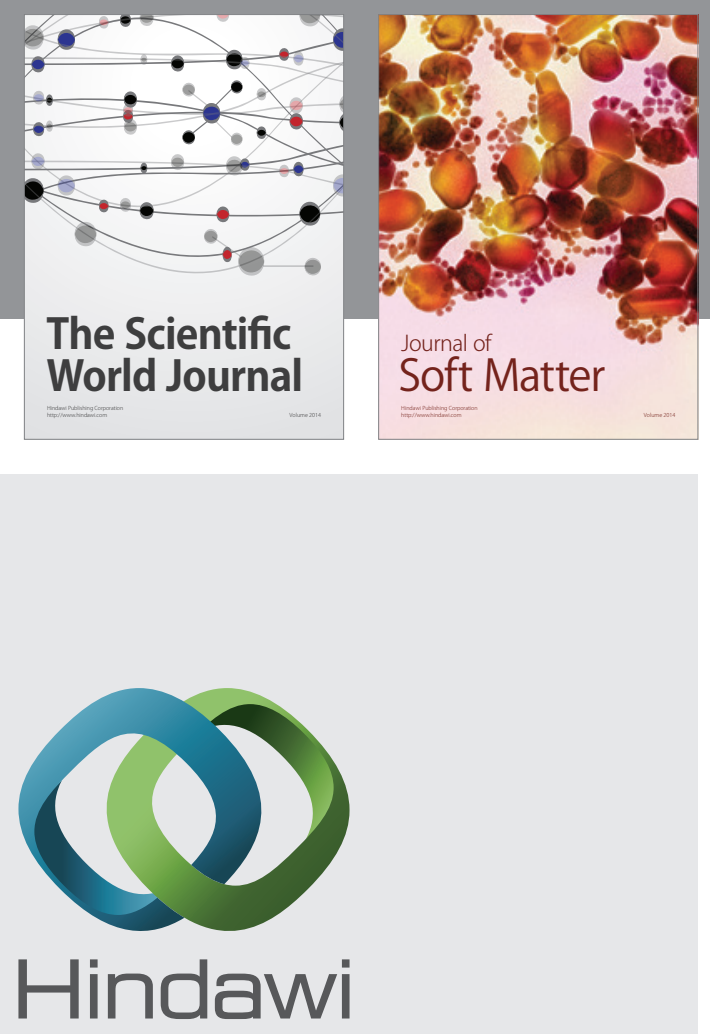

Submit your manuscripts at

http://www.hindawi.com
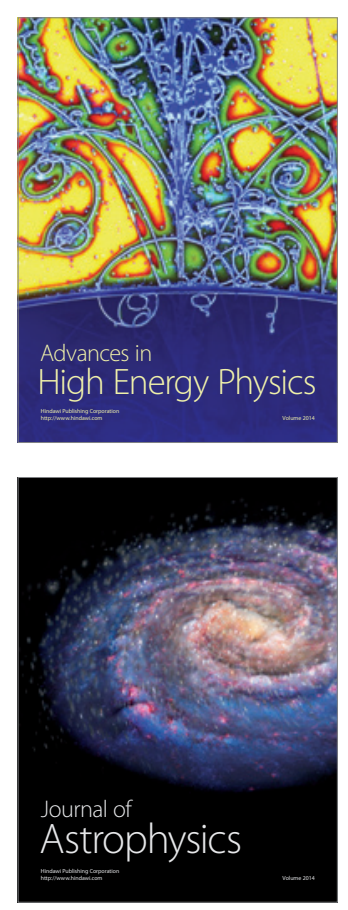
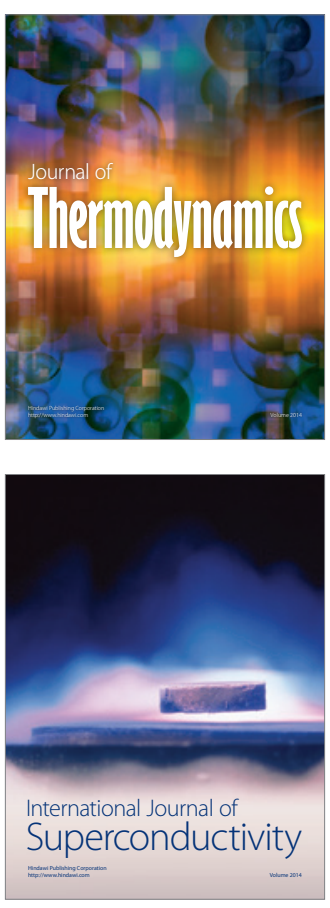
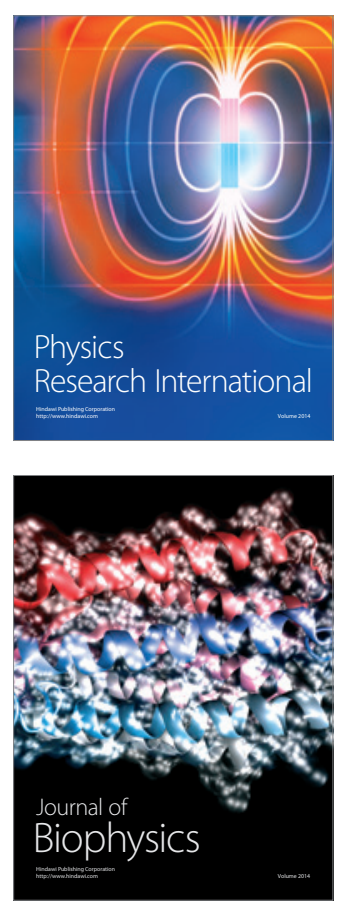
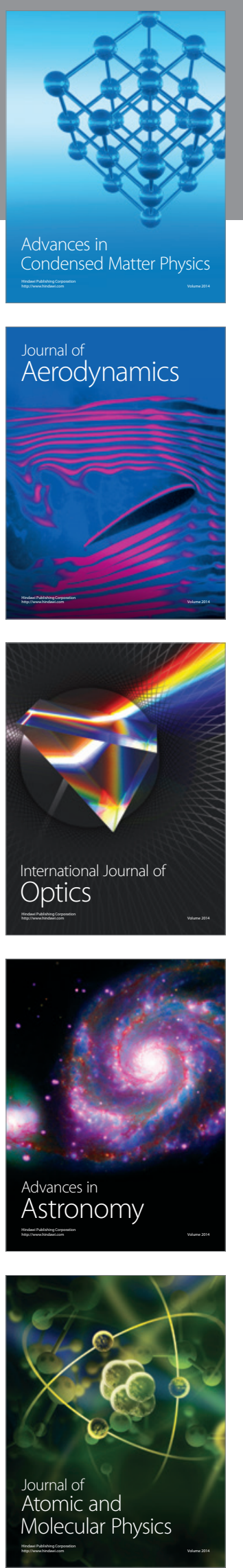